\title{
Das kann ins Auge gehen!
}

—Heuschnupfenpatienten mit juckenden und tränenden Augen sollten besser Brille tragen als Kontaktlinsen. Die Kontaktlinsen reizen die Augen zusätzlich und erhöhen die Gefahr von Konjunktividen, warnt die Augenärztin Dr. Gabriele Brumm, Hamburg.

Wenn die Augenbeteiligung nicht so stark ausfällt oder die Patienten nicht auf Kontaktlinsen verzichten möchten, sollten folgende Empfehlungen beherzigt werden:
- Die Kontaktlinsen müssen in der Pollensaison besonders sorgfältig gepflegt werden.

- Bei weichen Kontaktlinsen ist ein hoher Wassergehalt angenehmer.

- Tageslinsen reduzieren die Belastung der Augen durch Verunreinigungen.

- Antiallergische Augentropfen müssen kompatibel sein mit den Kontaktlinsen,

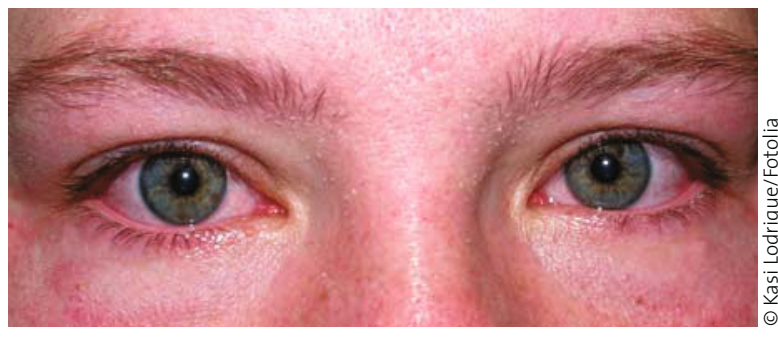

Wenn die Augen bei Heuschnupfen so stark mitleiden, sollten Kontaktlinsen besser draußen bleiben.

\section{PRÄVENTION DES PLÖTZLICHEN KINDSTODES Sechs lebensrettende Regeln}

\author{
_ Innerhalb von zehn Jahren sind die Fäl- \\ le von plötzlichem Kindstod (SIDS) in \\ Deutschland um mehr als die Hälfte zu- \\ rückgegangen. Im Jahr 1998 starben 602 \\ gesunde Babys ohne Vorwarnung, 2008 \\ waren es 215. Dieser Erfolg wurde allein \\ durch Aufklärung und das richtige Ver- \\ halten der Eltern erreicht. Die sechs evi- \\ denzbasierten Kernpunkte der Empfeh- \\ lungen für einen sicheren und gesunden \\ Babyschlaf lauten: \\ (1) Schlafposition in Rückenlage \\ (2) Verwendung von Babyschlafsäckchen \\ (3) Schlafen im eigenen Bettchen im El- \\ ternschlafzimmer \\ 4) Schutz vor Überwärmung
}

\section{Rauchfreie Wohnung 6 Stillen.}

Diese Erfolgsquote kann weiter verbessert werden, denn auch im Jahr 2007 schliefen nur 54\% der Babys konsequent auf dem Rücken. Selbst das Rauchen stellten 20\% der Frauen während der Schwangerschaft nicht ein, obwohl schon zehn Zigaretten pro Tag das Risiko für einen plötzlichen Kindstod um das Dreifache erhöhen. Auch in der Hausarztpraxis sollte die Gelegenheit zur Aufklärung über die vermeidbaren Risikofaktoren genutzt werden.

ST =

Stiftung Kindergesundheit, Klinische Pädiatrie 2009;221:1-6

\section{TOLLWUT UND ANDERE ZOONOSEN}

\section{Infektionsquelle Fledermaus}

- Nicht nur lateinamerikanische Vampirfledermäuse können Tollwut übertragen. Auch einige europäische, Insekten fressende Arten stehen seit Kurzem unter Verdacht. In Deutschland wurden bereits Tollwutvirusinfektionen bei Fledermäusen nachgewiesen. Weitere für den Menschen gefährliche Viren wie z. B. Henipaviren wurden kürzlich bei afrikanischen und asiatischen Flughunden entdeckt.
Da manche Fledermäuse bis zu Tausenden von Kilometern zurücklegen, müssen wir auch in unseren Breiten auf exotische Zoonosen gefasst sein. Dennoch ist die Fledermaus für unser Ökosystem extrem wichtig. Als Insektenvertilger schützt sie uns z. B. vor landwirtschaftlichen Schädlingen oder Moskitos.

ST =

Leibniz-Institut für Zoo- und Wildtierforschung, Berlin; doi: 10.1098/rsbl.2010.0267 die erst 15-30 Minuten nach dem Einträufeln eingesetzt werden sollten. BS .

Pressemeldung der Techniker Krankenkasse, 5. Mai 2010
Psychologie

\section{Mozart-Effekt widerlegt}

- Klassische Musik hat wohl doch keinen Einfluss auf die Intelligenz des Hörers. Das belegt eine Metaanalyse von Forschern der Universität Wien. Basierend auf einer Publikation der Psychologin Frances Rauscher aus dem Jahr 1993 war vermutet worden, dass speziell eine Mozart-Sonate für zwei Klaviere in D-Dur (KV 448) das räumliche Vorstellungsvermögen verbessert. Vor allem in der amerikanischen Öffentlichkeit schenkte man der These viel Beachtung. Nun haben die Wiener Forscher alle 39 Studien zum Thema statistisch ausgewertet. Ein musikspezifischer Effekt auf das Raumvorstellungsvermögen ließ sich nicht nachweisen. Der „Mozart-Effekt" entpuppt sich damit als Mythos der populären Psychologie.

No =

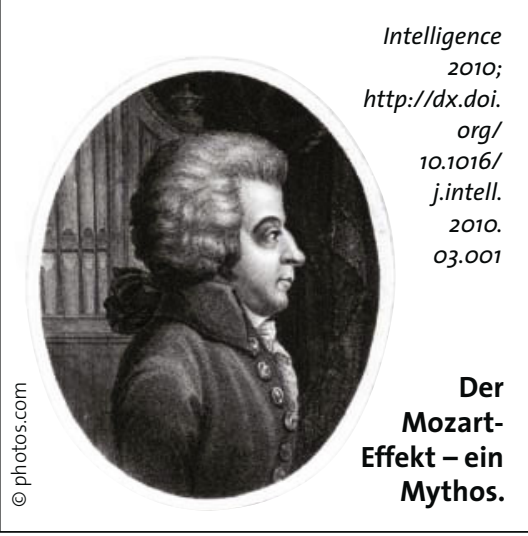

